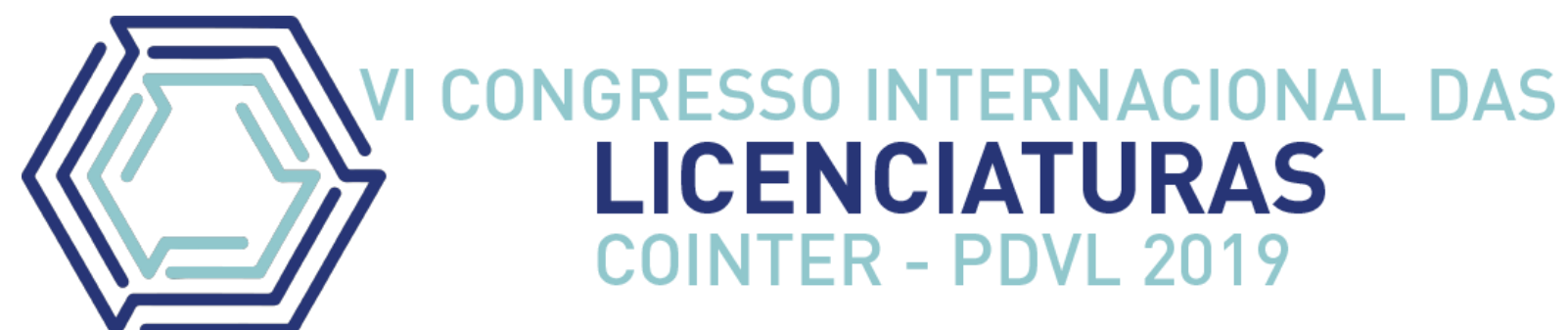

\title{
O PROGRAMA DE RESIDÊNCIA PEDAGÓGICA: UMA ALTERNATIVA PARA A APROXIMAÇÃO ENTRE O ACADÊMICO E O PROJETO POLITICO PEDAGÓGICO DA ESCOLA
}

\section{EL PROGRAMA DE RESIDENCIA PEDAGÓGICA: UNA ALTERNATIVA PARA ENFOQUE DEL PROYECTO DE POLÍTICA PEDAGÓGICA ESCOLAR}

\section{THE PEDAGOGICAL RESIDENCE PROGRAM: AN ALTERNATIVE FOR APPROACHING THE SCHOOL PEDAGOGICAL POLICY PROJECT}

\author{
Apresentação: Comunicação Oral \\ Eloiza Roza Dias da Costa ${ }^{1}$ J João Felix da Silva ${ }^{2}$; Maria das Graças Bento ${ }^{3}$ \\ DOI: https://doi.org/10.31692/2358-9728.VICOINTERPDVL.2019.0037
}

\begin{abstract}
Resumo
A pesquisa aborda a temática: "O Programa de Residência Pedagógica: uma alternativa para a aproximação entre o acadêmico e o Projeto Político Pedagógico da escola". Surgiu da necessidade de analisar a importância do PRP que tem como objetivo principal uma melhor formação inicial e avaliação dos futuros professores, por serem acompanhados e orientados no período que estão participando das atividades escolares na educação básica e refletir sobre a importância do PPP de uma escola, sendo escolhida para o estudo de caso a Escola de Educação Infantil e Ensino Fundamental Francisco Alves Gondim, localizada no Distrito Santo André em Penaforte-CE. O pesquisador é graduando do Curso de Pedagogia da Faculdade de Ciências humanas do Sertão Central, bolsista do PRP e realizou o Estagio Supervisionado na escola supracitada. O público alvo foi composto por 5 alunos do $9^{\circ}$ ano, 10 professores, 1 diretor, 1 coordenador, 1 secretária e 5 representantes de alunos da referida instituição Para a coleta de dados foram utilizados procedimentos variados como a observações do contexto escolar, diálogos proximais com a comunidade, participação ativa no cotidiano escolar, análise documental, narrativa oral, depoimentos, além de perguntas orais previamente elaboradas. A pesquisa, de natureza qualitativa, objetivou analisar e discutir a importância do PRP e PPP para o universitário do curso de Pedagogia enquanto professor ou gestor escolar. A pesquisa apresenta como problemática os seguintes questionamentos: $\mathrm{O}$ Programa Residência Pedagógica possibilitará melhorias significativas no desempenho do universitário em Pedagogia? O PPP é fundamental para que a escola trabalhe coletivamente, ouvindo todos os seus segmentos, compartilhando erros e acertos, caminhe na direção certa
\end{abstract}

1 -Graduanda do Curso Pedagogia, Faculdade de Ciências Humanas do Sertão Central, eloizaroza@gmail.com

2 - Psicopedagogo, FIP, joaofelixserrita@ hotmail.com

3- Mestre, Universidade Católica de Pernambuco, professoragracabento@ hotmail.com 
coletivamente. O PRP implica positivamente na qualidade da aprendizagem do graduando, que para continuar com a bolsa oriunda do programa busca empenhar-se para o cumprimento das atividades propostas e fazer jus a oportunidade recebida. Assim, seria justo e imprescindível que houvesse expansão das bolsas do PRP para todos os cursos de licenciatura.

Palavras-Chave: Residência Pedagógica, Projeto Pedagógico, Estágio.

\title{
Resumen
}

La investigación aborda el tema: "El Programa de Residencia Pedagógica: una alternativa para el enfoque entre el proyecto político académico y pedagógico de la escuela". Surgió de la necesidad de analizar la importancia de PRP, que tiene como objetivo principal una mejor formación inicial y evaluación de futuros maestros, ya que están acompañados y orientados en el período en que participan en actividades escolares en educación básica y reflexionan sobre la importancia de PPP en una escuela. , siendo elegido para el estudio de caso, la Escuela de Educación Infantil y Educación Primaria Francisco Alves Gondim, ubicada en el distrito de Santo André en Penaforte-CE. El investigador se graduó del Curso de Pedagogía de la Facultad de Ciencias Humanas de la Sertão Central, becario de PRP y realizó la pasantía supervisada en la escuela mencionada. El público objetivo consistió en 5 estudiantes del noveno grado, 10 maestros, 1 director, 1 coordinador, 1 secretario y 5 representantes de estudiantes de esa institución. Para la recolección de datos, se utilizaron varios procedimientos, como observaciones del contexto escolar, diálogos cercanos con la comunidad, participación activa en la vida escolar diaria, análisis documental, narrativa oral, testimonios, así como preguntas orales previamente elaboradas. La investigación, de naturaleza cualitativa, tuvo como objetivo analizar y discutir la importancia de PRP y PPP para el estudiante del curso de Pedagogía como maestro o gerente de la escuela. La investigación presenta como problemáticas las siguientes preguntas: ¿Permitirá el Programa de Residencia Pedagógica mejoras significativas en el desempeño del estudiante universitario en Pedagogía? PPP es fundamental para que la escuela trabaje colectivamente, escuche todos sus segmentos, comparta errores y aciertos, y se mueva en la dirección correcta colectivamente. El PRP implica positivamente la calidad del aprendizaje del estudiante, que para continuar con la beca del programa busca esforzarse por cumplir con las actividades propuestas y estar a la altura de la oportunidad recibida. Por lo tanto, sería justo y esencial para las becas PRP expandirse a todos los cursos de pregrado.

Palabra clave: Residencia Pedagógica, Proyecto Pedagógico, Pasantía.

\begin{abstract}
The research addresses the theme: "The Pedagogical Residence Program: an alternative for the approach between the academic and the Pedagogical Political Project of the school." It arose from the need to analyze the importance of PRP, which has as its main objective a better initial formation and evaluation of future teachers, as they are accompanied and oriented in the period that they are participating in school activities in basic education and reflect on the importance of PPP in a school. , being chosen for the case study the School of Early Childhood Education and Elementary Education Francisco Alves Gondim, located in the Santo André District in Penaforte-CE. The researcher is a graduate of the Pedagogy Course of the Faculty of Human Sciences of the Central Sertão, a PRP scholarship holder and held the Supervised Internship at the aforementioned school. The target audience consisted of 5
\end{abstract}


students from the 9th grade, 10 teachers, 1 principal, 1 coordinator, 1 secretary and 5 student representatives from that institution. For data collection, various procedures were used, such as observations of the school context, close dialogues with the community, active participation in daily school life, documentary analysis, oral narrative, testimonials, as well as oral questions previously elaborated. The research, qualitative in nature, aimed to analyze and discuss the importance of PRP and PPP for the student of the Pedagogy course as a teacher or school manager. The research presents as problematic the following questions: Will the Pedagogical Residency Program allow significant improvements in the performance of the university student in Pedagogy? PPP is critical for the school to work collectively, listening to all its segments, sharing errors and hits, and moving in the right direction collectively. The PRP positively implies the quality of the student's learning, which to continue with the scholarship from the program seeks to strive to fulfill the proposed activities and to live up to the opportunity received. Thus, it would be fair and essential for PRP scholarships to expand to all undergraduate courses.

Keyword: Pedagogical Residence, Pedagogical Project, Internship.

\section{Introdução}

É indispensável que o professor tenha habilidades e competências para uma atuação satisfatória em sala de aula ou na gestão escolar. Porém, para que ocorra a aquisição dessas competências exigidas para o bom desempenho do professor ou gestor é necessária a vivência de uma ação teórico-prática, isto é, não basta que tenha teoria, mas fazer uma articulação desta com a prática, com o fazer pedagógico de forma reflexiva, constatando o que deve ser preservado ou modificado na teoria (PARECER CNE/CP/2001)

Em outubro de 2018, foi possível perceber o quanto a prática é significativa para um profissional, especialmente para o professor, após o inicio da participação no Programa Residência Pedagógica (PRP) na Escola de Educação Infantil e Ensino Fundamental Francisco Alves Gondim, localizada no Distrito Santo André em Penaforte-CE. Esse programa tem como objetivo principal uma melhor formação inicial e avaliação dos futuros professores, por serem acompanhados e orientados no período que estão participando das atividades escolares na educação básica. O programa mantém uma parceria com instituições formadoras e convênios com redes públicas de ensino.

O PRP favorece a ampliação do conhecimento do universitário, especialmente no tocante à prática em sala de aula, ações desenvolvidas por um gestor escolar e principalmente a importância do Projeto Político Pedagógico (PPP) que direciona os trabalhos da escola tornando-a mais democrática e participativa, uma vez que é construído coletivamente por todos que fazem parte da comunidade escolar. 
O Projeto Político Pedagógico é uma ferramenta de planejamento e avaliação fundamental para definir a identidade da escola e os caminhos que ela irá percorrer para fornecer um ensino de qualidade. É essencial para que a escola tenha uma gestão democrática. Deve ser elaborado por gestores, professores, funcionários, alunos e representantes de alunos, contemplando valores, a missão escolar, sua identidade e outros. O PPP é uma ferramenta de planejamento e avaliação fundamental para definir a identidade da escola e os caminhos que ela irá percorrer para oferecer um ensino de qualidade.

A presente pesquisa científica cuja temática é "O Programa de Residência Pedagógica: uma alternativa para a aproximação entre o acadêmico e o Projeto Político Pedagógico da escola”, objetiva analisar e discutir a importância do PRP e PPP para o universitário do curso de Pedagogia enquanto professor ou gestor escolar. A pesquisa é de natureza qualitativa, um estudo de caso tendo como contexto a Escola de Educação Infantil e Ensino Fundamental Francisco Alves Gondim e o público alvo composto por alunos, professores e gestores e representantes de alunos da referida instituição.

Inicialmente foi realizado um estudo bibliográfico para maiores conhecimentos sobre a temática escolhida, seguido de observações do contexto escolar, diálogos com a comunidade, participação ativa no cotidiano escolar, inclusive em reuniões referentes ao PPP, documento que proporciona uma escola participativa e com decisões compartilhadas. A importância do PPP está expressa no pensamento de Lück, (2010, p. 17) Quando afirma que “Ao se referir às escolas e sistemas de ensino, o conceito de gestão participativa envolve além dos professores e funcionários, os pais, os alunos e qualquer outro representante da comunidade que esteja interessado na escola e na melhoria do processo pedagógico".

A pesquisa apresenta como problemática os questionamentos: o Programa Residência Pedagógica possibilitará melhorias significativas no desempenho do universitário do Curso de Pedagogia? O PPP da escola pode torná-la democrática? É notório que o PRP é um programa que oportuniza ao universitário o estabelecimento de uma relação teoria/prática indispensável a sua formação acadêmica. Quanto ao PPP, especialmente na atualidade, é fundamental para que a escola caminhe na direção certa com a participação coletiva.

O estudo justifica-se por verificar a utilidade de um programa como o PRP para a melhoria da atuação dos profissionais de ensino. Através do programa o graduando passa a ter um maior conhecimento, na prática, sobre o papel do PPP na escola e sua execução e avaliação. Durante a residência há um contato maior com a prática das teorias adquiridos na 
instituição de Ensino Superior (IES). Pretende-se com os resultados dessa pesquisa informar aos futuros universitários a importância do programa para sua atuação futura.

\section{Fundamentação Teórica}

A Escola é uma instituição promotora de educação sistemática e desenvolvimento das potencialidades do sujeito para que possa com eficiência e eficácia desempenhar seu papel social e ser construtor da sua própria história. Seu processo contínuo de transmissão, construção e desenvolvimento de conhecimentos, culturas e valores, é fundamental para o crescimento pessoal e coletivo, capaz de modificar a maneira de ser e agir dos sujeitos sociais. Essa instituição existe para proporcionar as crianças, adolescentes, jovens e adultos, aquisição de habilidades e competências inerentes ao exercício da cidadania plena, conforme explicitado na Constituição Federal de 1988, Estatuto da Criança e do Adolescente e a Lei de Diretrizes e Bases da Educação Nacional e Suas Resoluções.

Para que a escola ofereça ao sujeito uma educação de qualidade, não basta que tenha uma escola bem estruturada, prédio moderno, materiais de consumo e permanentes suficientes, mas uma equipe com habilidades e competências capaz de desenvolver as potencialidades do sujeito preparando-o para a vida. Seus recursos humanos, especialmente professores e gestores deverão estar aptos para o exercício da função, ou seja, sua prática pedagógica ser coerente com o objetivo da educação sistemática, o papel para o qual se propõe o sistema educacional. De acordo com Young (2007, p. 1288), as escolas têm um papel muito importante e são "[...] instituições com o propósito específico de promover a aquisição do conhecimento [...]". Somente elas são responsáveis pelo conhecimento específico.

O sistema educacional já passou ao longo do tempo por muitas mudanças em busca de inovações e melhorias. A escola é um contexto dessas mudanças, especialmente no tocante à formação dos seus professores e gestores para a conquista de uma educação de qualidade. Ela apresenta-se como local onde a dignidade da vida constitui-se como referencial maior na construção de uma sociedade justa e fraterna. Muitos programas são propostos para que a escola atinja seus objetivos.

Um dos programas é a Residência Pedagógica, criado através do Projeto de Lei n. 284, datado de 2012, de autoria do Senador Blairo Maggi, sendo uma das ações da Política Nacional de Formação de Professores. Seu objetivo é incentivar o aperfeiçoamento de uma 
formação pratica nos cursos de licenciatura, proporcionando ao licenciando um espaço na escola de educação básica para adquirir a prática relacionada à teoria recebida no curso superior a partir da segunda metade do curso.

O programa contempla diversas atividades e entre elas tem destaque a regência de sala de aula e intervenção pedagógica. O contemplado ou a contemplada pelo programa recebe acompanhamento de um professor da escola com experiência na área de ensino do universitário, além da orientação que recebe de um docente da sua Instituição Formadora. "Importa analisar o que acontece, como, por que, onde, com quem e quando acontecem determinadas situações buscando um novo sentido diante do que está sendo observado e aprendido no processo junto à realidade observada" (CALDERANO, 2012, p.251).

O programa é desenvolvido pela Coordenação de Aperfeiçoamento de Pessoal de Nível Superior (Capes), autarquia vinculada ao MEC. Existe em todos os estados brasileiros e são muitas as escolas da rede municipal e estadual de ensino que participam. Muitas instituições de ensino superior já firmaram acordo com a Capes e muitos universitários são contemplados com o programa recebendo bolsas que facilitam a permanência na instituição de ensino superior, principalmente quando é um aluno de baixo poder aquisitivo. É uma modernização do Programa Institucional de Bolsas de Iniciação à Docência (Pibid).

A residência pedagógica de acordo com o Edital CAPE (06/2018) [...] consiste na imersão planejada e sistemática do aluno de licenciatura em ambiente escolar visando à vivência e experimentação de situações concretas do cotidiano escolar e da sala de aula que depois servirão de objeto de reflexão sobre a articulação entre teoria e prática [...] (Edital CAPES, 06/2018).

Panizzolo afirma que:

(...) Ao articular o processo formativo inicial do pedagogo com as práticas educativas dos educadores das escolas públicas e a preceptoria dos professores da universidade o PRP tem potencializado o diálogo entre as referências teóricas historicamente acumuladas na área da educação e as práticas vivenciadas nas escolas públicas, tecendo assim a articulação entre a formação universitária e a formação continuada. (PANIZZOLO, 2012, p. 5).

O Programa de Residência Pedagógica é um aperfeiçoamento do estágio curricular supervisionado nos cursos de licenciatura, preparando o sujeito para atuar satisfatoriamente nas escolas de educação básica. Oferece quatro modalidades de bolsa: residente, coordenador institucional, docente orientador e preceptor. De acordo com matéria publicada no site da 
CAPES (www.capes.gov.br/educacaobasica/programa-residencia-pedagogica01/03/2018), o PRP tem como objetivos:

1. Aperfeiçoar a formação dos discentes de cursos de licenciatura, por meio do desenvolvimento de projetos que fortaleçam o campo da prática e conduzam o licenciando a exercitar de forma ativa a relação entre teoria e prática profissional docente, utilizando coleta de dados e diagnóstico sobre o ensino e a aprendizagem escolar, entre outras didáticas e metodologias;

2. Induzir a reformulação do estágio supervisionado nos cursos de licenciatura, tendo por base a experiência da residência pedagógica;

3. Fortalecer, ampliar e consolidar a relação entre a IES e a escola, promovendo sinergia entre a entidade que forma e a que recebe o egresso da licenciatura e estimulando o protagonismo das redes de ensino na formação de professores;

4. Promover a adequação dos currículos e propostas pedagógicas dos cursos de formação inicial de professores da educação básica às orientações da Base Nacional Comum Curricular (BNCC).

O Programa de Residência Pedagógica, na interface com o Estágio Supervisionado, proporciona ao graduando uma prática mais proveitosa no contexto escolar, é um vínculo muito positivo entre as IES e a escola. O graduando é bem orientado para o cumprimento das suas tarefas na escola, conta com a colaboração dos professores, gestores da escola, além de um coordenador e preceptor do programa. O estágio curricular é uma etapa indispensável para a formação do graduando, é uma forma adequada para por a teoria recebida em prática, convier com a realidade de uma escola, observar seus principais documentos, especialmente o Projeto Político Pedagógico. Esse documento é um dos mais importantes da escola, propõe o melhor caminho para organizar o trabalho pedagógico.

Veiga afirma que:

O Projeto Político Pedagógico ao se constituir em processo democrático de decisões preocupa-se em instaurar uma forma de organização do trabalho pedagógico que supere os conflitos, buscando eliminar as relações competitivas, corporativas e autoritárias, rompendo com a rotina do mando impessoal e racionalizado da burocracia que permeia as relações no interior da escola (VEIGA, 2007, p.13).

O PPP é um documento que orienta o trabalho escolar, muito importante, principalmente, por destacar o desenvolvimento de cada habilidade ética do ser humano, tais como: ser condutor de uma consciência crítica, reflexiva; poder meditar para uma tomada de decisões coerentes com as situações preexistentes; saber respeitar a si mesmo e aos outros, respeitando as regras de convivência em sociedade; reconhecer diante das situações seus diretos e deveres; buscar o aperfeiçoamento e atitudes corretas; cultivar uma cultura de 
justiça, fraternidade, esperança, afetividade e solidariedade humana; respeito à diversidade; manter uma boa convivência entre o grupo de trabalho que deve ser pautada pelo conhecimento, colaboração e pela cooperação que constrói um ambiente de troca constante de experiências profissionais e autoestima no que faz e agir com transparência.

Para Veiga (2002, p.2):

A principal possibilidade de construção do Projeto Político Pedagógico passa pela relativa autonomia da escola, de sua capacidade de delinear sua própria identidade. Isto significa resgatar a escola como espaço público, lugar de debate, do diálogo, fundado na reflexão coletiva. Portanto, é preciso entender que o projeto políticopedagógico da escola dará indicações necessárias à organização do trabalho pedagógico, que inclui o trabalho do professor na dinâmica interna da sala de aula, ressaltado anteriormente.

O Projeto Político Pedagógico é um planejamento de trabalho participativo, coletivo, reflexivo que deve atender as necessidades de aprendizagens locais, estimulando a criticidade e a criatividade de discentes, docentes e dos demais profissionais que atuam de maneira otimista na tarefa de educar. Propõe mudanças com compromisso sério a toda sociedade educativa, dando sugestões que expressam o desejo de todos os que fazem a educação. Para que o PPP seja um documento que realmente possa determinar os caminhos viáveis para o sucesso escolar é necessário que seu gestor conheça o passado da instituição e o presente para adquirir subsídios que orientem corretamente as ações que serão implementadas. Como afirma Silva (2014, p. 11): “Gerir uma instituição escolar sem dar atenção ao presente e ao passado é arriscar a organização, pois é no presente e no passado que estão as referências concretas para se prospectar novas ações prevenindo os erros e as insuficiências e intensificando os êxitos verificados".

\section{Metodologia}

No iniciado de outubro de 2018 teve inicio a participação da pesquisadora no cotidiano da Escola Francisco Alves Gondim, no Distrito Santo André, através do Programa Residência Pedagógica. Esse programa proporcionou um espaço de interação entre pesquisador e instituição de ensino, conhecendo melhor o espaço escolar, elaboração e execução do PPP, atuação da gestão e outros.

A pesquisa, que optou por um estudo de caso, teve inicio com um estudo bibliográfico para conseguir subsídios teóricos significativos para a fundamentação da temática em questão. É de natureza qualitativa, e o contexto é a Escola de Educação Infantil e Ensino Fundamental Francisco Alves Gondim, sendo o público alvo composto por 5 alunos do $9^{\circ}$ ano, 10 
professores, 1 diretor, 1 coordenador, 1 secretária e 5 representantes de alunos da referida instituição.

Para coletar os dados foram utilizados importantes instrumentos metodológicos: a observação direta do contexto escolar, diálogos proximais com a comunidade, participação ativa no cotidiano escolar, inclusive em reuniões referentes ao PPP, análise documental, narrativa oral, depoimentos, além de perguntas orais previamente elaboradas dirigidas ao núcleo gestor e docentes da escola com o objetivo de conhecer a percepção do público alvo sobre o cotidiano escolar. Portanto, após estas observações elaboramos um questionamento: o Projeto Político Pedagógico é um mecanismo educacional para uma gestão democrática e participativa na Escola? Tudo isso foi suficiente para coletar os dados necessários à pesquisa, que posteriormente foram analisados cuidadosamente e transformados em um relatório.

\section{Resultados e Discussão}

O artigo apresenta os resultados coletados a partir de um estudo de caso, de caráter qualitativo na Escola de Educação Infantil e Ensino Fundamental Francisco Alves Gondim, localizada no Distrito Santo André, pertencente ao município de Penaforte. Atualmente funciona nos turnos manhã e tarde atendendo crianças e adolescentes da pré-escola ao $9^{\circ}$ ano de Ensino Fundamental e Educação de Jovens e Adultos. A direção da escola é constituída por um Diretor, um Coordenador Pedagógico e uma Secretária Escolar. Conta com uma equipe de professores capacitados, além de auxiliares administrativos, auxiliares de serviços gerais e vigias. O trabalho é realizado em articulação entre SEDE e Distrito, onde todos buscam atender os anseios dos alunos, oferecendo-lhes uma linha de ação pedagógica conjunta para que o grupo educacional possa conquistar as condições favoráveis para o exercício de sua cidadania plena num processo sólido e contínuo de transformação do saber empírico em saber sistematizado

A seguir serão apresentados depoimentos do núcleo gestor da escola relacionado ao atendimento oferecido à comunidade rural, na qual a escola está inserida:

A escola oferece uma educação eficiente e preparatória para a vida, pois seus profissionais estão em constante formação em serviço, participando de qualificações dentro de suas respectivas áreas do conhecimento. A escola tem um trabalho pautado na inclusão social, em decisões compartilhadas, na liderança democrática para cumprir com eficiência e eficácia o seu papel (DIRETORA). 
Atualmente a Escola atende a crianças e adolescentes da pré-escola ao $9^{\circ}$ ano de Ensino Fundamental. Também atende a Educação de Jovens e Adultos, com projetos específicos para essa modalidade de ensino, buscando equacionar a distorção idade/série da clientela que não teve oportunidade de concluir seus estudos na idade certa (SECRETÁRIA).

Artigo $n^{\circ} 37$ da Lei de Diretrizes e Bases - Lei 9394/96, $§ 1^{\circ}, 2^{\circ}$ e $3^{\circ}$,afirma que:

Art. 37. A educação de jovens e adultos será destinada àqueles que não tiveram acesso ou continuidade de estudos nos ensinos fundamental e médio na idade própria e constituirá instrumento para a educação e a aprendizagem ao longo da vida. (Redação dada pela Lei nº 13.632, de 2018).

§ $\mathbf{1}^{\circ}$ Os sistemas de ensino assegurarão gratuitamente aos jovens e aos adultos, que não puderam efetuar os estudos na idade regular, oportunidades educacionais apropriadas, consideradas as características do alunado, seus interesses, condições de vida e de trabalho, mediante cursos e exames.

§ $2^{\circ} \mathrm{O}$ Poder Público viabilizará e estimulará o acesso e a permanência do trabalhador na escola, mediante ações integradas e complementares entre si.

§ 3o A educação de jovens e adultos deverá articular-se, preferencialmente, com a educação profissional, na forma do regulamento. (Incluído pela Lei $\mathrm{n}^{\circ} 11.741$, de 2008)

O núcleo gestor da escola é composto por um diretor, um coordenador pedagógico e uma secretária. Os gestores, professores, funcionários, alunos e seus representantes trabalham em parceria, cumprindo o regimento escolar e o seu PPP. Todas as decisões são compartilhadas para que a escola possa tornar possível o cumprimento do seu importante papel de educar para a vida. As ações são elaboradas e executadas coletivamente com o propósito mais amplos que é responder às expectativas e às exigências da comunidade escolar e consequentemente da sociedade (COORDENADORA)

Os professores, através de diálogos com o pesquisador, depoimentos, narrativas e questionamentos, mostraram como é o ensino e aprendizagem. Foi possível coletar informações significativas do cotidiano escolar. A seguir serão transcritos alguns depoimentos dos professores, sendo um de cada ano ( $1^{\circ}$ ano, $2^{\circ}$ ano, $3^{\circ}$ ano, $4^{\circ}$ ano, $5^{\circ}$ ano,...EJA), totalizando 10 professores.

A Escola Francisco Alves Gondim oferece à comunidade ensino de qualidade que contribui para o desenvolvimento da autonomia responsável, do senso crítico e da criatividade dos alunos para o exercício da cidadania. Sempre trabalha oportunizando o desenvolvimento dos seus alunos em todos os aspectos como a responsabilidade, criticidade, criatividade, capacidade de análise, enfim, ser construtor da sua própria história (PROFESSOR DO 5ANO, 2019)

Buscamos Educar para a transformação da realidade social, valorizando a vida e a dignidade humana, orientada pelo conhecimento e pela ética. Orientamos nossos alunos para construírem seu próprio projeto de vida de forma responsável durante o seu percurso formativo. Proporcionamos aos alunos os instrumentos para a 
aprendizagem de valores e conhecimentos por meio de estimulação frequente. Avaliamos constantemente nossas ações para constatarmos pontos fortes e fracos e adotarmos ações de correção. Também avaliamos quantitativamente e qualitativamente nossos alunos através de diversos instrumentos para constatarmos erros e acertos e assim, conjuntamente adotarmos medidas de melhorias (PROFESSOR DO 2ANO, 2019)

A escola funciona em dois turnos e conta com uma equipe de professores capacitados e instigados a buscar, através de capacitações e estudo, um maior aprimoramento da sua prática pedagógica. A escola dispõe de biblioteca equipada e um laboratório de informática para a realização de trabalhos educativos como a pesquisas em horários de aulas e em contra turno. Os alunos são orientados a pesquisar e desenvolver o gosto pela leitura (PROFESSOR DO $3^{\circ} \mathrm{ANO}, 2019$ )

A escola Francisco Alves Gondim, apesar de ter boa estrutura, biblioteca equipada, laboratório de informática, oferecer merenda escolar de qualidade, contar com uma equipe de professores estimulados e preparados para exercer a docência, ela também tem problemas e dificuldades que precisam ser contornadas. Nos diálogos com o diretor e professores, na ocasião de um encontro pedagógico da escola, foram discutidos e analisados os principais problemas e as melhores soluções.

Assim como em toda escola, principalmente da rede pública, temos algumas dificuldades e tentamos solucioná-las na medida do possível. Essas dificuldades são variadas e repercutem na aprendizagem do aluno, evasão escolar, reprovação, baixo índice de desempenho, principalmente nas avaliações externas. Esses problemas são muito debatidos pela comunidade escolar em diversas ocasiões, principalmente nas reuniões de pais e reuniões de professores que acontecem frequentemente e no inicio do ano letivo já são determinadas no calendário escolar. Dentre os problemas mais preocupantes estão: indisciplina do aluno, falta de participação efetiva de alguns pais no cotidiano escolar, aluno desestimulado, baixa condição socioeconômica, e outras(PROFESSOR DO $7^{\circ} \mathrm{ANO}, 2019$ ).

Tabela 1: Dificuldades enfrentadas pela escola X soluções

\begin{tabular}{|c|c|}
\hline DIFICULDADES & ENFRENTAMENTO \\
\hline $\begin{array}{lr}\text { Ausência } & \text { dos } \\
\text { representantes } & \text { de } \\
\text { alunos } & \\
\end{array}$ & $\begin{array}{l}\text { Visitas domiciliares mantendo um diálogo aberto com a família do } \\
\text { aluno. }\end{array}$ \\
\hline $\begin{array}{l}\text { Baixo índice de } \\
\text { rendimento do aluno }\end{array}$ & $\begin{array}{l}\text { Analisar a metodologia do professor, reunião com os representantes } \\
\text { do aluno para expor o problema e pedir ajuda, oferecer reforço no } \\
\text { contra turno, conversar com o aluno para ouvir as causas do baixo } \\
\text { rendimento. Os professore planejarem atividades desafiadoras e } \\
\text { interessantes, proporcionar capacitação para os professores. }\end{array}$ \\
\hline Evasão escolar & $\begin{array}{l}\text { Visitas domiciliares para diálogos com os pais e com o aluno } \\
\text { evadido tentando o retorno à escola. }\end{array}$ \\
\hline
\end{tabular}




\begin{tabular}{|l|l|}
\hline Reprovação & $\begin{array}{l}\text { Acompanhamento quinzenal do desempenho do aluno para adotar } \\
\text { medidas corretivas quando apresentar desempenho insatisfatório, } \\
\text { como reforçar conteúdos utilizando a biblioteca e o laboratório de } \\
\text { informática, usar atividades atrativas, está atendo aos sinais de } \\
\text { dificuldade dos alunos, adotar a recuperação contínua, entre outras. }\end{array}$ \\
\hline Indisciplina & $\begin{array}{l}\text { Dialogar com o aluno e a família para descobrir a causa da } \\
\text { indisciplina. Utilizar atividades diferenciadas e envolventes para } \\
\text { estimular a atenção do aluno e motivando-o a querer aprender e ser } \\
\text { mais disciplinado. }\end{array}$ \\
\hline Infrequência & $\begin{array}{l}\text { Conversar com o aluno e entrar em contato com a família para } \\
\text { descobrir os motivos do não comparecimento à escola, propor ajuda, } \\
\text { investir em tecnologia para tornar o ambiente escolar mais atrativo, } \\
\text { diversificar a metodologia de ensino, etc. }\end{array}$ \\
\hline Desinteresse & $\begin{array}{l}\text { Descobrir através do diálogo com o aluno a causa do seu } \\
\text { desinteresse, acolher bem o aluno de modo que ele perceba sua } \\
\text { importância, conversar com a família sobre o problema, verificar se } \\
\text { o aluno tem dificuldade de aprendizagem, elogiá-lo à medida que } \\
\text { for demonstrando mudanças positiva, propor ajuda, etc. }\end{array}$ \\
\hline
\end{tabular}

Fonte: Própria (2019)

Para a escola cumprir sua missão, trabalha priorizando o coletivo e adotando uma liderança compartilhada. O núcleo gestor procura ouvir a opinião de todos na resolução dos problemas. Valoriza e garante a formação continuada para seus professores e demais profissionais da escola, pois sabe que um professor com competências e habilidade, com formação acadêmica adequada consegue, em sala de aula, realizar um trabalho promissor, Estimulando o desenvolvimento das crianças e adolescentes em seus aspectos sociais, intelectuais, emocionais, respeitando o seu ritmo de aprendizagem.

Procuramos manter aproximação com a família do aluno para sabermos a opinião relacionada ao nosso trabalho. Ouvimos seus depoimentos e indagamos sobre sugestões que possam melhorar o trabalho da escola, assim conhecermos os pontos negativos e podermos eliminar do cotidiano escolar. Sabemos o quanto é importante a escola trabalhar em parceria com os pais dos nossos alunos, eles sentem que a escola é para eles e passam a valorizá-la mais (PROFESSOR DO $8^{\circ}$ E $9^{\circ}$ ANO, 2019).

Os pais de alunos que participaram da pesquisa afirmaram que:

A escola é muito boa, aqui os alunos são bem acolhidos, valorizados e respeitados. $\mathrm{O}$ relacionamento de todos que trabalham aqui é muito bonito. Todos da escola desejam que o aluno aprenda muito, se desenvolva. A escola está sempre convidando os pais para conversar sobre os filhos, o comportamento, desempenho, para participar de reuniões para discutir melhorias para a escola, dizer o que está bom e o que não está. A opinião dos pais é muito valorizada e respeitada.Nós somos incentivados a participar da escola, pois o diretor e os professores sempre dizem que a participação dos pais é fundamental para o bom desempenho do aluno (PAIS DE ALUNOS, 2019). 
Os alunos participantes da pesquisa afirmaram que a escola é um ambiente acolhedor e são muito valorizados por todos. Gostam muito da escola, da maneira como a maioria dos professores ensinam. A escola oferece biblioteca para pesquisa e é um ambiente bonito e acolhedor, tem laboratório de informática e uma quadra para a prática de esportes. Os professores cumprem com suas atividades e são amigos dos alunos.

Sempre trabalhamos coletivamente compartilhando experiências e opiniões. Existem problemas pontuais como a indisciplina do aluno, falta de interesse, baixo desempenho, mas são solucionados por todos da escola. A equipe pedagógica está sempre avaliando as metodologias utilizadas e buscando inovações que favoreçam o desempenho escolar, especialmente o aprendizado do aluno (PROFESSOR DO $\left.4^{\circ} \mathrm{ANO}, 2019\right)$.

Nossa escola tem um PPP elaborado com a participação de todos os segmentos obedecendo a Lei de Diretrizes e Bases da Educação Nacional (LDBEN 9.394/96), e assim, ele orienta nosso trabalho, é a nossa cartilha, o guia para nossas ações. Norteia nossas ações, determina metas a atingir, princípios e valores. Buscamos as melhores soluções legais para os problemas e por isso nosso índice de acertos é significativamente superior ao de erros (PROFESSOR DO 6º ANO, 2019).

O Projeto Político Pedagógico da escola é um documento que reúne a opinião de todos, traz os objetivos que se deseja atingir, as diretrizes e ações capazes de melhorar o processo educativo culminando com as expectativas sociais relacionadas ao desempenho da escola. Esse documento elaborado de forma democrática e colaborativa é obrigatório e de livre acesso a comunidade escolar. Toda a equipe é unânime em afirma que com o PPP a escola adquire maior identidade. Desta forma é notório que a escola utiliza o instrumento citado acima como um mecanismo educacional, pois é visível a coletividade em todo ambiente escolar.

A escola conta com a colaboração de um residente pedagógico, que participa ativamente das suas atividades, inclusive da sala de aula. Todos os professores e gestores afirmam que é uma iniciativa bem-sucedida e aproxima muito a instituição de Ensino Superior da escola de educação básica. O programa está acertando, é uma parceria que proporciona bons resultados para a escola, IES e principalmente para o residente que está tendo a oportunidade de unir a teoria recebida no seu curso a pratica na escola de educação básica.

Desta forma é visível a importância do PRP, seria muito valida a ampliação das bolsas para que atendesse mais graduandos, pois o programa residência pedagógica contribui com o 
andamento escolar, principalmente quando a escola é democrática.

\section{Conclusões}

Concluída a pesquisa foi possível verificar que o Programa Residência Pedagógica tem contribuído significativamente para a formação inicial do graduando, uma vez que possibilita, a esse aluno ainda cursando alguma licenciatura, vivenciar na prática diversas situações de socialização à docência. É um estágio muito produtivo, principalmente porque além do graduando está adquirindo variadas experiências, também recebe uma bolsa que, em muitos casos é o único recurso que dispõe para cumprir com custos financeiros advindos do curso.

Observando o cotidiano escolar, tendo a oportunidade de analisar e até participar da elaboração dos principais documentos da escola, especialmente do PPP, o residente sente-se mais seguro e preparado para exercer uma docência e ou gestão escolar com competência e habilidade. Assim, é possível afirmar que o PRP implica positivamente na qualidade da aprendizagem do graduando, que para continuar com a bolsa oriunda do programa busca empenhar, separa o cumprimento das atividades propostas e fazer jus a oportunidade recebida.

Seria justo e imprescindível que houvesse expansão das bolsas do PRP para todos os cursos de licenciatura, pois seria um grande incentivo para quem almeja ingressar em uma faculdade e concluir um curso com mais preparo, competências e habilidades. Também é justo lembrar que muitos sujeitos não dispõem de recursos financeiros e em inúmeros casos precisam abandonar o curso por esse motivo. Portanto o PRP representa um vínculo entre a teoria e a prática, estreita os laços entre as instituições de ensino superior e a escola, proporciona uma formação inicial e continuada ao graduando, portanto é uma alternativa viável para uma formação adequada dos profissionais de educação. Pois diante do observado na pesquisa a escola busca meios para ampliar a participação de outros sujeitos, como forma de atribuir maiores elos entre tais sujeitos em prol da qualidade das práticas que são realizadas no âmbito escolar.

O aprendizado no período de residência é indiscutivelmente satisfatório, principalmente quando o graduando foi contemplado com uma bolsa do PRP, pois uma das vantagens desse programa é reduzir as limitações dos estágios curriculares. Verifica-se que a escola norteia seu trabalho pelo PPP que foi elaborado com a participação da comunidade 
escolar e, principalmente com representantes de alunos, fortalecendo a democratização da escola.

O Projeto Político Pedagógico tem como foco a formação de valores éticos, filosóficos e políticos educacionais, os quais norteiam o comportamento do ser humano nas diversas dimensões, tais como: respeito mútuo, autonomia, liderança, ética, dedicação pelo belo, cooperação, aperfeiçoamento dos aspectos conceituais, atitudinais e procedimentais Princípios Pedagógicos e Filosóficos da Educação. Portanto, PPP é fundamental para que a escola trabalhe coletivamente, ouvindo todos os seus segmentos, compartilhando erros e acertos, caminhe na direção certa coletivamente.

\section{Referências}

BRASIL. Constituição da República Federativa do Brasil: D.O. 5 de outubro de 1988. Disponível em:<www.mec.gov.br/legis/default.shtm>. Acesso em: 20 jan. 2019.

Conselho Nacional de Educação. Do parecer no tocante as diretrizes curriculares nacionais para a formação de professores da educação básica, em nível superior, curso de licenciatura, de graduação plena. Parecer normativo, n. 009/2001 de 08 de maio de 2001. Relatora: Raquel Figueiredo Alessandri Teixeira. MEC/SESU

.Edital CAPES 06/2018 que dispõe sobre a Residência Pedagógica. Disponível em <https://www.capes.gov.br/images/stories/download/editais/01032018-Edital-6-2018esidencia-pedagogica.pdf $>$. Acesso em 12 mar. 2018.

Estatuto da Criança e do Adolescente. Normativas Internacionais. Conveções $\mathbf{N}^{0}$ s 138 e 182, e Recomendação N$^{0} 190$ - OIT. Portaria $N^{\circ}$ 6/2002 - TEM. Ministério da Justiça/ Secretaria de Estado dos Direitos Humanos/Departamento da Criança e do Adolescente (DCA)/ Conselho Nacional dos Direitos da Criança e do Adolescente (Conanda). Brasília: 2002.

- Lei de Diretrizes e Bases da Educação Nacional, no 9394, de 20 de dezembro de1996. Disponível em:<http://www.planalto.gov.br/ccivil_03/leis/19394.htm>. acesso em: 10 jan. 2019.

CALDERANO, M. da A. O estágio curricular e os cursos de formação de professores: desafios de uma proposta orgânica. In: CALDERANO, M. da A. (Org.). Estágio curricular: concepções, reflexões teórico-práticas e proposições. Juiz de fora: Editora UFJF, 2012. p. 237-260.

LÜCK, H. A escola participativa:o trabalho do gestor escolar. 8ed. Petrópolis - Rio de Janeiro: Vozes, 2010. 
PANIZZOLO, C. et al. Programa de Residência Pedagógica da Unifesp: Avanços e desafios para a implantação de propostas inovadoras de estágio. In: Políticas de Formação Inicial e Continuada de Professores. XVI ENDIPE - Encontro Nacional de Didática e Práticas de Ensino. Campinas, anais... 2012.

Programa de Residência Pedagógica. Disponível em <https:// www.capes.gov.br/educacao basica/programa-residencia-pedagogica $>$. Publicada em 01/03/2018. Acesso em: 25 maio2019

SILVA, A. J. da Gestão do Projeto Pedagógico - Guarapuva: UAB, Unicentro, 2014. (Coleção Gestão Escolar e Contemporaneidade, 4).

VEIGA, I. P. (0rg.). Quem sabe faz a hora de construir o Projeto Político Pedagógico da escola. Campinas, São Paulo: Papirus, 2007.

YOUNG, M. Para que servem as escolas? Campinas, vol. 28, n. 101, p. 1287- 1302, set./dez. 2007. Disponível em: <https://www. Cedes. Unicamp.br >.Acesso em: 25 mar. 2019. 